\title{
Prognostic Impact of Atrial Fibrillation and New Risk Score of Its Onset in Patients at High Risk of Heart Failure - A Report From the CHART-2 Study -
}

\author{
Takeshi Yamauchi, MD, PhD; Yasuhiko Sakata, MD, PhD; Masanobu Miura, MD, PhD; \\ Takeo Onose, MD; Kanako Tsuji, MD; Ruri Abe, MD; Takuya Oikawa, MD; \\ Shintaro Kasahara, MD; Masayuki Sato, MD; Kotaro Nochioka, MD, PhD; \\ Takashi Shiroto, MD, PhD; Jun Takahashi, MD, PhD; Satoshi Miyata, PhD; \\ Hiroaki Shimokawa, MD, PhD on behalf of the CHART-2 Investigators
}

\begin{abstract}
Background: The prognostic impact of atrial fibrillation (AF) among patients at high risk for heart failure (HF) remains unclear. In addition, there is no risk estimation model for AF development in these patients.

Methods and Results: The present study included 5,382 consecutive patients at high risk of HF enrolled in the CHART-2 Study $(n=10,219)$. At enrollment, 1,217 (22.6\%) had AF, and were characterized, as compared with non-AF patients, by higher age, lower estimated glomerular filtration rate, higher B-type natriuretic peptide (BNP) level and lower left ventricular ejection fraction. A total of 116 non-AF patients (2.8\%) newly developed AF (new AF) during the median 3.1-year follow-up. AF at enrollment was associated with worse prognosis for both all-cause death and HF hospitalization (adjusted hazard ratio (aHR) 1.31, P=0.027 and aHR 1.74, $\mathrm{P}=0.001$, for all-cause death and $\mathrm{HF}$ hospitalization, respectively) and new $\mathrm{AF}$ was associated with HF hospitalization (aHR 4.54, $P<0.001$ ). We developed a risk score with higher age, smoking, pulse pressure, lower eGFR, higher BNP, aortic valvular regurgitation, LV hypertrophy, and left atrial and ventricular dilatation on echocardiography, which effectively stratified the risk of AF development with excellent accuracy (AUC 0.76).
\end{abstract}

Conclusions: These results indicated that $\mathrm{AF}$ is associated with worse prognosis in patients at high risk of HF, and our new risk score may be useful to identify patients at high risk for AF onset.

Key Words: Atrial fibrillation; Heart failure; Prognosis; Risk score

A trial fibrillation (AF) is a common arrhythmia that affects approximately $1.0 \%$ of the general population. ${ }^{1-3}$ Furthermore, the prevalence of $\mathrm{AF}$ is higher in elderly people and has been increasing with global aging. ${ }^{1-4} \mathrm{AF}$ is also an independent predictor of death, heart failure (HF) and stroke, ${ }^{5-8}$ although appropriate therapy, such as anticoagulation, improves the prognosis of patients. ${ }^{910}$ Patients with chronic HF (CHF) have a markedly higher prevalence of AF (17-38\%) than the general population. ${ }^{11-13} \mathrm{We}$ recently reported that approximately $35 \%$ of patients with Stage C/D HF had AF as a comorbidity and that new-onset AF, but not AF at enrollment, was associated with worse prognosis in HF patients, especially in the first year after onset. ${ }^{11}$ However, the prognostic impact of $\mathrm{AF}$ among patients with $\mathrm{CHF}$ is still controversial.11-13
The American College of Cardiology Foundation (ACCF) and the American Heart Association (AHA) have recommended classifying $\mathrm{HF}$ patients into Stages $\mathrm{A} / \mathrm{B} / \mathrm{C} / \mathrm{D}$ based on the stage of progression. ${ }^{14}$ Stage A HF corresponds to patients with a high risk of HF without structural heart disease, Stage B HF is used to classify patients with structural heart disease but without symptomatic HF, and Stages C/D correspond to symptomatic HF. ${ }^{14} \mathrm{AF}$ is associated with worse prognosis among the general population and patients with coronary artery disease (CAD). ${ }^{58,15}$ In addition, it was previously reported that new-onset of $\mathrm{AF}$ is associated with increased incidence of subsequent $\mathrm{HF}$ in the general population, ${ }^{16}$ indicating that $\mathrm{AF}$ in Stage $\mathrm{A} / \mathrm{B}$ HF patients is an important risk factor for HF exacerbation. Thus, prevention and early identification of $\mathrm{AF}$ may help to prevent HF progression, particularly among

Received July 28, 2016; revised manuscript received November 23, 2016; accepted November 27, 2016; released online January 14, 2017 Time for primary review: 31 days

Department of Cardiovascular Medicine (T.Y., Y.S., M.M., T. Onose, K.T., R.A., T. Oikawa, S.K., M.S., K.N., T.S., J.T., H.S.), Department of Evidence-Based Cardiovascular Medicine (S.M., H.S.), Tohoku University Graduate School of Medicine, Sendai, Japan

Mailing address: Yasuhiko Sakata, MD, PhD, Department of Cardiovascular Medicine, Tohoku University Graduate school of Medicine, 1-1 Seiryo-machi, Aoba-ku, Sendai 980-8574, Japan. E-mail: sakatayk@cardio.med.tohoku.ac.jp

ISSN-1346-9843 All rights are reserved to the Japanese Circulation Society. For permissions, please e-mail: cj@j-circ.or.jp 


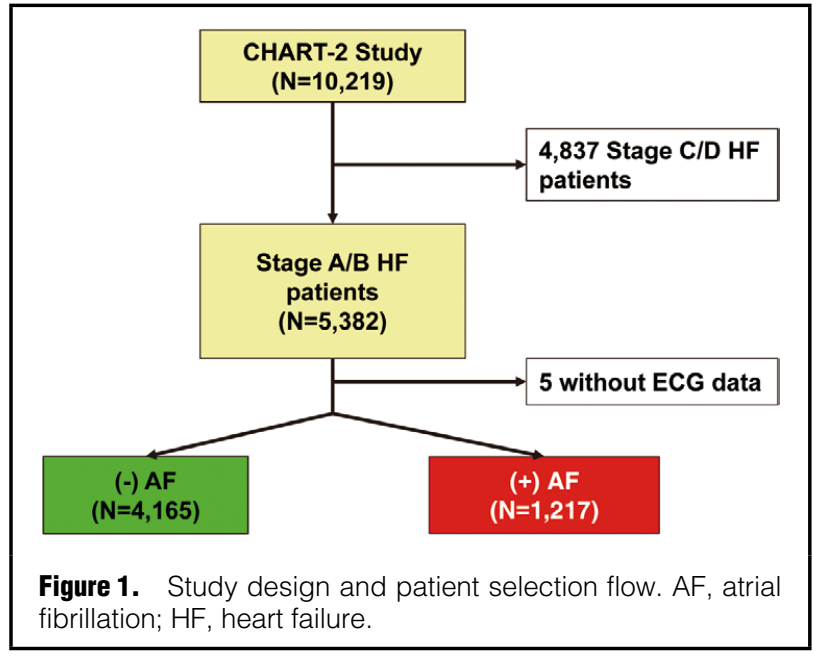

those in Stage A/B. However, the prognostic impact of AF in patients with Stage $\mathrm{A} / \mathrm{B} \mathrm{HF}$ remains to be elucidated.

Paroxysmal AF (pAF) and non-paroxysmal AF (npAF) are associated with similar risks for stroke. ${ }^{17}$ Using mobile cardiac outpatient telemetry, AF was detected in $23 \%$ of patients with cryptogenic stroke. ${ }^{18}$ Thus, the detection of paroxysmal or asymptomatic AF is clinically important; however, these conditions are often overlooked in regular clinical evaluations, including medical examination, ECG and/or laboratory analysis. Although long-term ECG recordings are useful for detecting AF, they are usually used for screening of AF in patients with suspected symptoms. Thus, the development of a simple and sensitive method to identify patients at high risk of AF would enable us to perform a 12-lead or Holter ECG recording with appropriate frequencies.

Patients at high risk of AF can be treated with reninangiotensin system (RAS) inhibitors or statins, which lower blood pressure and are reported to reduce the onset of AF.19-22 To date, several risk scores for AF have been developed. ${ }^{23-25}$ However, although the previous scores achieve high area under the curve (AUC) values, they are complex and based on physical or ECG findings alone, and do not include laboratory or echocardiographic data. Moreover, these risk scores were developed using data obtained from the general population and mainly included individuals with white and black ancestry. Thus, the development of a simple and accurate score that includes objective assessment parameters, such as laboratory and echocardiographic data, is needed to more accurately assess AF risk in patients at high risk of AF. In addition, considering the fact that the number of patients with $\mathrm{AF}$ and HF has been dramatically increasing in Asia, ${ }^{26-29}$ a useful model for risk prediction in Asian populations has been awaited.

In the present study, we thus examined the prevalence, characteristics and prognostic impact of AF in Stage A/B $\mathrm{HF}$ patients and aimed to develop a risk score for AF onset, using the database of our Chronic Heart Failure Analysis and Registry in the Tohoku District-2 (CHART-2) Study. ${ }^{30-34}$

\section{Methods}

\section{The CHART-2 Study}

The CHART-2 Study $(\mathrm{n}=10,219)$ is a multicenter, prospective observational study, as previously described (NCT00418041). ${ }^{30-34}$ Patients aged $\geq 20$ years with significant $\mathrm{CAD}$ or in Stage $\mathrm{B} / \mathrm{C} / \mathrm{D} \mathrm{HF}$, as defined according to the ACCF/AHA guidelines, ${ }^{14}$ were consecutively enrolled from October 2006 to March $2010 .^{30-34}$ Clinical information was recorded at the time of enrollment and thereafter reviewed annually by trained clinical research coordinators. The CHART-2 Study was approved by the local ethics committees of each participating hospital and written informed consent was given by all patients. ${ }^{30-34}$

\section{Study Design}

The flowchart of the present study is shown in Figure 1. Among the 10,219 patients enrolled in the CHART-2 Study, 5,387 were identified in Stage A (CAD) or Stage B HF, and 5 were excluded for lack of ECG data. Among the 5,382 patients with Stage A/B HF, 1,217 $(22.6 \%)$ had AF and $4,165(77.4 \%)$ had no AF at enrollment. AF was diagnosed by cardiologists at each institute according to the clinical guidelines of the Japanese Circulation Society. ${ }^{35}$ AF was defined as 'new AF' when documented for the first time in patients without AF at enrollment. We compared the clinical characteristics, therapies and long-term prognosis. Comparisons were made in terms of AF at enrollment, new-onset AF, type of AF (pAF vs. npAF), and combined factors for new-onset of AF and type of AF. The endpoints of the study included all-cause death, HF hospitalization, cardiovascular (CV) death and non-CV death. To examine the prognostic impact of new-onset AF, we compared the incidence of each endpoint between patients with $\mathrm{AF}$ at enrollment and those who developed AF without prior HF hospitalization. The patients were divided into 3 groups according to their risk score (low, intermediate, or high), and the prognosis of patients with new-onset AF was compared among the groups. In the present study, valvular heart disease (VHD) was defined as severe aortic and/or mitral valvular disease, which was diagnosed on echocardiography using standard criteria. Hypertension (HT) as an etiology was considered when a patient did not have ischemic heart disease (IHD), dilated cardiomyopathy (DCM), hypertrophic cardiomyopathy (HCM) or VHD, but had a history of HT.

\section{Statistical Analysis}

All continuous variables are reported as mean \pm SD or median and interquartile range (IQR) and all categorical variables are reported as frequency (percentage). Welch's t-test and Fisher's exact test were used to compare the continuous and categorical variables, respectively. The Kaplan-Meier method and log-rank test were used to estimate survival curves and HF-free survival curves, respectively. Multivariable Cox proportional hazard models were used to assess the effect of AF on all-cause death and HF hospitalization. The covariates used in each multivariable analysis were selected using a stepwise method ${ }^{\mathbf{3 6}}$ from the following factors: sex, age, body mass index (BMI), systolic blood pressure (BP), diastolic BP, heart rate, history of HT, diabetes mellitus (DM), dyslipidemia, smoking, stroke and malignant disease, etiologies of $\mathrm{CHF}$, including IHD, DCM, HCM, VHD and HT, left atrial dimension (LAd), end-diastolic left ventricular (LV) dimension (LVDd), 
LV ejection fraction (LVEF), estimated glomerular filtration rate (eGFR), mean corpuscular volume of red blood cells, hemoglobin, B-type natriuretic peptide (BNP), New York Heart Association (NYHA) class, and medical treatment, including $\beta$-blockers, calcium-channel blockers (CCB), RAS inhibitors, diuretics, statins, antiplatelet drugs, and warfarin. Among these covariates, sex, age, BMI, history of DM, stroke and malignant disease, LVDd, LVEF, eGFR, hemoglobin, NYHA class, CCB and antiplatelet drugs were selected for analysis of all-cause death.

Risk scores for the development of new-onset AF were developed based on the results of multivariable logistic regression model analysis. During this process, variables were selected using the following criteria: the use of drugs and a history of HT, dyslipidemia, or DM were excluded in order to minimize the potential effects of drugs. Etiologies were also excluded because invasive procedures (e.g., catheter placement) were needed to define etiology. Continuous variables were converted into categorical variables using classification and regression trees (CART) to decide the most appropriate cutoff points. ${ }^{37}$ In the CART analysis, each subgroup, lower or upper than the cutoff point, must have more than 208 in number to include at least 5\% of patients without AF at enrollment, because subgroups with lower prevalence do not likely present the characteristics of patients with Stage B HF.

Finally, the following factors were used to develop risk scores for new-onset AF: sex, age $\geq 60$ years, BMI $\geq 30 \mathrm{~kg} / \mathrm{m}^{2}$,

\begin{tabular}{|c|c|c|c|c|}
\hline A & $\begin{array}{c}\text { All } \\
(n=5,382)\end{array}$ & $\begin{array}{c}(-) \text { AF } \\
(n=4,165)\end{array}$ & $\begin{array}{c}(+) \mathrm{AF} \\
(\mathrm{n}=1,217)\end{array}$ & $P$ value \\
\hline Female, n, \% & $1,564(29.1)$ & 1,221 (29.3) & $343(28.2)$ & 0.451 \\
\hline Age, years & $67.6 \pm 12.0$ & $66.8 \pm 12.3$ & $70.5 \pm 10.4$ & $<0.001$ \\
\hline BMI, $\mathbf{k g} / \mathrm{m}^{2}$ & $24.2 \pm 3.5$ & $24.3 \pm 3.4$ & $24.1 \pm 3.6$ & 0.242 \\
\hline \multicolumn{5}{|l|}{ Etiology, n, \% } \\
\hline IHD & $3,229(60.0)$ & $2,830(67.9)$ & $399(32.8)$ & $<0.001$ \\
\hline $\mathrm{DCM}$ & $135(2.5)$ & $80(1.9)$ & $55(4.5)$ & $<0.001$ \\
\hline $\mathrm{HCM}$ & 225 (4.2) & $162(3.9)$ & $63(5.2)$ & 0.051 \\
\hline VHD & $423(7.9)$ & $263(6.3)$ & $160(13.1)$ & $<0.001$ \\
\hline HT & $1,079(20.0)$ & $631(15.2)$ & $448(36.8)$ & $<0.001$ \\
\hline \multicolumn{5}{|l|}{ Risk factors, $n, \%$} \\
\hline HT & 4,652 (86.4) & 3,589 (86.2) & 1,063 (87.3) & 0.318 \\
\hline DM & 1,591 (29.6) & $1,310(31.5)$ & $281(23.1)$ & $<0.001$ \\
\hline Dyslipidemia & $4,310(80.1)$ & $3,432(82.4)$ & $878(72.1)$ & $<0.001$ \\
\hline Smoking & $2,469(48.5)$ & $1,974(50.1)$ & $495(43.0)$ & $<0.001$ \\
\hline \multicolumn{5}{|l|}{ Previous history, n, \% } \\
\hline MI & $1,440(26.8)$ & $1,280(30.7)$ & $160(13.1)$ & $<0.001$ \\
\hline Stroke & $960(17.8)$ & $649(15.6)$ & $311(25.6)$ & $<0.001$ \\
\hline Malignant disease & $711(13.2)$ & $511(12.3)$ & $200(16.4)$ & $<0.001$ \\
\hline \multicolumn{5}{|c|}{ Hemodynamics and LV function } \\
\hline Systolic BP, mmHg & $130.2 \pm 17.8$ & $130.8 \pm 17.9$ & $128.3 \pm 17.4$ & $<0.001$ \\
\hline Diastolic BP, mmHg & $74.7 \pm 11.5$ & $74.6 \pm 11.5$ & $74.8 \pm 11.5$ & 0.687 \\
\hline Heart rate, beats/min & $69.7 \pm 13.2$ & $69.1 \pm 12.5$ & $72.0 \pm 15.0$ & $<0.001$ \\
\hline LVDd, mm & $48.6 \pm 6.8$ & $48.4 \pm 6.8$ & $49.0 \pm 6.7$ & 0.014 \\
\hline LAd, mm & $39.5 \pm 7.5$ & $37.8 \pm 6.1$ & $45.1 \pm 8.9$ & $<0.001$ \\
\hline LVEF, \% & $64.9 \pm 11.5$ & $65.2 \pm 11.6$ & $63.6 \pm 10.9$ & $<0.001$ \\
\hline LVWT, mm & $11.0 \pm 2.2$ & $10.9 \pm 2.2$ & $11.2 \pm 2.2$ & $<0.001$ \\
\hline \multicolumn{5}{|l|}{ Laboratory findings } \\
\hline Hemoglobin, g/dL & $13.6 \pm 1.7$ & $13.6 \pm 1.7$ & $13.7 \pm 1.8$ & 0.098 \\
\hline eGFR, $\mathrm{mL} / \mathrm{min} / 1.73 \mathrm{~m}^{2}$ & $67.3 \pm 19.3$ & $68.3 \pm 19.5$ & $64.0 \pm 18.5$ & $<0.001$ \\
\hline Albumin, mg/dL & $4.2 \pm 0.4$ & $4.2 \pm 0.4$ & $4.1 \pm 0.5$ & 0.152 \\
\hline LDL-C, mg/dL & $106.4 \pm 29.3$ & $106.1 \pm 29.1$ & $107.6 \pm 29.9$ & 0.166 \\
\hline BNP, pg/mL & $\begin{array}{c}47.2 \\
(20.8-113.0)\end{array}$ & $\begin{array}{c}37.0 \\
(18.1-81.3)\end{array}$ & $\begin{array}{c}106.0 \\
(51.8-195.2)\end{array}$ & $<0.001$ \\
\hline \multicolumn{5}{|l|}{ Medications, n, \% } \\
\hline$\beta$-blockers & 1,773 (32.9) & $1,319(31.7)$ & $454(37.3)$ & $<0.001$ \\
\hline RAS inhibitors & $3,123(58.0)$ & $2,449(58.8)$ & $674(55.4)$ & 0.035 \\
\hline Diuretics & $875(16.3)$ & $559(13.4)$ & $316(26.0)$ & $<0.001$ \\
\hline Statins & $2,389(44.4)$ & $2,057(49.4)$ & 332 (27.3) & $<0.001$ \\
\hline Digitalis & 477 (8.9) & $111(2.7)$ & $366(30.1)$ & $<0.001$ \\
\hline
\end{tabular}

(Table 1 continued the next page.) 


\begin{tabular}{|c|c|c|c|c|c|c|c|c|}
\hline B & $\begin{array}{c}\text { All } \\
(n=5,382)\end{array}$ & $\begin{array}{c}(-) \text { New AF } \\
(n=4,049)\end{array}$ & $\begin{array}{c}\text { (+) New AF } \\
(n=116)\end{array}$ & $P$ value & $\underset{\substack{\text { pAF } \\
(n=516)}}{ }$ & $\begin{array}{c}\text { cAF } \\
(n=701)\end{array}$ & $P$ value & $\begin{array}{l}P \text { value } \\
\text { (overall) }\end{array}$ \\
\hline Female sex, n, \% & $1,564(29.1)$ & 1,186 (29.3) & $35(30.2)$ & 0.836 & $160(31.0)$ & $183(26.1)$ & 0.062 & 0.244 \\
\hline Age, years & $67.6 \pm 12.0$ & $66.7 \pm 12.3$ & $69.7 \pm 10.1$ & 0.002 & $70.4 \pm 11.3$ & $70.6 \pm 9.6$ & 0.698 & $<0.001$ \\
\hline BMI, $\mathbf{k g} / \mathrm{m}^{2}$ & $24.2 \pm 3.5$ & $24.3 \pm 3.4$ & $24.6 \pm 3.6$ & 0.250 & $23.9 \pm 3.4$ & $24.3 \pm 3.8$ & 0.085 & 0.524 \\
\hline \multicolumn{9}{|l|}{ Etiology, n, \% } \\
\hline IHD & $3,229(60.0)$ & 2,763 (68.2) & $67(57.8)$ & 0.020 & 213 (41.3) & $186(26.5)$ & $<0.001$ & $<0.001$ \\
\hline DCM & $135(2.5)$ & $79(2.0)$ & $1(0.9)$ & 0.727 & $5(1.0)$ & $50(7.1)$ & $<0.001$ & $<0.001$ \\
\hline $\mathrm{HCM}$ & $225(4.2)$ & $152(3.8)$ & $10(8.6)$ & 0.014 & $34(6.6)$ & $29(4.1)$ & 0.066 & 0.004 \\
\hline VHD & $423(7.9)$ & $252(6.2)$ & $11(9.5)$ & 0.171 & $52(10.1)$ & $108(15.4)$ & 0.008 & $<0.001$ \\
\hline $\mathrm{HT}$ & $1,079(20.0)$ & $607(15.0)$ & $24(20.7)$ & 0.113 & $168(32.6)$ & 280 (39.9) & 0.010 & $<0.001$ \\
\hline \multicolumn{9}{|l|}{ Risk factors, $n, \%$} \\
\hline HT & $4,652(86.4)$ & 3,488 (86.1) & $101(87.1)$ & 0.892 & $438(84.9)$ & 625 (89.2) & 0.029 & 0.124 \\
\hline DM & $1,591(29.6)$ & 1,279 (31.6) & $31(26.7)$ & 0.310 & $111(21.5)$ & $170(24.3)$ & 0.271 & $<0.001$ \\
\hline Dyslipidemia & $4,310(80.1)$ & $3,338(82.4)$ & $94(81.0)$ & 0.710 & $396(76.7)$ & $482(68.8)$ & 0.002 & $<0.001$ \\
\hline Smoking & $2,469(48.5)$ & $1,916(49.9)$ & $58(55.8)$ & 0.274 & $209(42.4)$ & $286(43.5)$ & 0.719 & $<0.001$ \\
\hline \multicolumn{9}{|l|}{ Previous history, n, \% } \\
\hline MI & $1,440(26.8)$ & $1,250(30.9)$ & $30(25.9)$ & 0.263 & $80(15.5)$ & $80(11.4)$ & 0.040 & $<0.001$ \\
\hline Stroke & $960(17.8)$ & $631(15.6)$ & $18(15.5)$ & 1.000 & $109(21.1)$ & $202(28.8)$ & 0.003 & $<0.001$ \\
\hline Malignant disease & $711(13.2)$ & $485(12.0)$ & $26(22.4)$ & 0.002 & $82(15.9)$ & $118(16.8)$ & 0.696 & $<0.001$ \\
\hline \multicolumn{9}{|l|}{$\begin{array}{l}\text { Hemodynamics and LV } \\
\text { function }\end{array}$} \\
\hline Systolic BP, mmHg & $130.2 \pm 17.8$ & $130.8 \pm 17.9$ & $130.3 \pm 18.2$ & 0.757 & $129.7 \pm 17.9$ & $127.3 \pm 16.9$ & 0.023 & $<0.001$ \\
\hline Diastolic BP, mmHg & $74.7 \pm 11.5$ & $74.7 \pm 11.5$ & $71.9 \pm 10.9$ & 0.007 & $74.5 \pm 11.2$ & $75.0 \pm 11.8$ & 0.511 & 0.849 \\
\hline Heart rate, beats/min & $69.7 \pm 13.2$ & $69.1 \pm 12.5$ & $67.8 \pm 13.3$ & 0.285 & $68.7 \pm 14.1$ & $74.4 \pm 15.1$ & $<0.001$ & $<0.001$ \\
\hline LVDd, mm & $48.6 \pm 6.8$ & $48.4 \pm 6.8$ & $50.2 \pm 7.3$ & 0.012 & $47.9 \pm 6.7$ & $49.7 \pm 6.6$ & $<0.001$ & $<0.001$ \\
\hline LAd, mm & $39.5 \pm 7.5$ & $37.7 \pm 6.1$ & $41.7 \pm 6.8$ & $<0.001$ & $40.5 \pm 7.0$ & $48.5 \pm 8.6$ & $<0.001$ & $<0.001$ \\
\hline LVEF, \% & $64.9 \pm 11.5$ & $65.3 \pm 11.6$ & $63.1 \pm 12.4$ & 0.070 & $66.0 \pm 10.5$ & $61.9 \pm 10.9$ & $<0.001$ & $<0.001$ \\
\hline LVWT, mm & $11.0 \pm 2.2$ & $10.9 \pm 2.2$ & $11.6 \pm 2.6$ & 0.011 & $11.2 \pm 2.3$ & $11.2 \pm 2.1$ & 0.911 & $<0.001$ \\
\hline \multicolumn{9}{|l|}{ Laboratory findings } \\
\hline Hemoglobin, g/dL & $13.6 \pm 1.7$ & $13.6 \pm 1.7$ & $13.4 \pm 1.7$ & 0.188 & $13.4 \pm 1.7$ & $13.8 \pm 1.8$ & $<0.001$ & 0.018 \\
\hline eGFR, $\mathrm{mL} / \min 1.73 \mathrm{~m}^{2}$ & $67.3 \pm 19.3$ & $68.4 \pm 19.5$ & $64.7 \pm 18.5$ & 0.038 & $63.2 \pm 19.4$ & $64.5 \pm 17.8$ & 0.232 & $<0.001$ \\
\hline Albumin, mg/dL & $4.2 \pm 0.4$ & $4.2 \pm 0.4$ & $4.1 \pm 0.4$ & 0.030 & $4.1 \pm 0.4$ & $4.1 \pm 0.5$ & 0.378 & 0.129 \\
\hline LDL-C, mg/dL & $106.4 \pm 29.3$ & $106.0 \pm 29.2$ & $107.5 \pm 25.1$ & 0.619 & $108.3 \pm 30.4$ & $107.1 \pm 29.5$ & 0.549 & 0.198 \\
\hline $\mathrm{BNP}, \mathrm{pg} / \mathrm{mL}$ & $\begin{array}{c}47.2 \\
(20.8-113.0)\end{array}$ & $\begin{array}{c}36.3 \\
(17.7-79.0)\end{array}$ & $\begin{array}{c}82.2 \\
(33.9-190.6)\end{array}$ & $<0.001$ & $\begin{array}{c}70.1 \\
(30.2-140.1)\end{array}$ & $\begin{array}{c}139 \\
(80.3-223.4)\end{array}$ & $<0.001$ & $<0.001$ \\
\hline \multicolumn{9}{|l|}{ Medications, n, \% } \\
\hline$\beta$-blockers & $1,773(32.9)$ & $1,273(31.4)$ & $46(39.7)$ & 0.068 & $184(35.7)$ & $270(38.5)$ & 0.337 & 0.002 \\
\hline RAS inhibitors & $3,123(58.0)$ & $2,377(58.7)$ & $72(62.1)$ & 0.504 & 278 (53.9) & $396(56.5)$ & 0.382 & 0.105 \\
\hline Diuretics & 875 (16.3) & $533(13.2)$ & $26(22.4)$ & 0.008 & 84 (16.3) & 232 (33.1) & $<0.001$ & $<0.001$ \\
\hline Statins & $2,389(44.4)$ & $2,007(49.6)$ & $50(43.1)$ & 0.187 & $155(30.0)$ & $177(25.2)$ & 0.068 & $<0.001$ \\
\hline Digitalis & 477 (8.9) & $101(2.5)$ & $10(8.6)$ & 0.001 & $86(16.7)$ & 280 (39.9) & $<0.001$ & $<0.001$ \\
\hline
\end{tabular}

$\mathrm{AF}$, atrial fibrillation; BNP, B-type natriuretic peptide; BP, blood pressure; BMI, body mass index; DCM, dilated cardiomyopathy; DM, diabetes mellitus; eGFR, estimated glomerular filtration rate; HCM, hypertrophic cardiomyopathy; HF, heart failure; HT, hypertension; IHD, ischemic heart disease; LAd, left atrial dimension; LDL-C, low-density lipoprotein cholesterol; LV, left ventricular; LVDd, end-diastolic left ventricular dimension; LVEF, left ventricular ejection fraction; LVWT, LV wall thickness; MI, myocardial infarction; NYHA, New York Heart Association; RAS, renin-angiotensin system; VHD, valvular heart disease.

pulse pressure $\geq 65 \mathrm{mmHg}$, diastolic $\mathrm{BP} \geq 70 \mathrm{mmHg}$, heart rate $\geq 60$ beats/min, history of stroke, smoking, eGFR $\leq 65 \mathrm{~mL} / \mathrm{min} / 1.73 \mathrm{~m}^{2}$, BNP $70-175 \mathrm{pg} / \mathrm{mL}, \mathrm{BNP} \geq 175 \mathrm{pg} / \mathrm{mL}$, aspartate aminotransferase (AST) $\geq 50 \mathrm{IU} / \mathrm{L}$ or alanine aminotransferase $(A L T) \geq 50 \mathrm{IU} / \mathrm{L}$, uric acid $\geq 6 \mathrm{mg} / \mathrm{dL}$, LAd $\geq 45 \mathrm{~mm}$, LVDd $\geq 55 \mathrm{~mm}$, mean LV wall thickness $($ LVWT $) \geq 14 \mathrm{~mm}$ and LVEF $\leq 45 \%$. Next, a multivariable logistic regression model and a stepwise method were used to develop the risk scores for new-onset AF in the following 4 models. Model 1 included physical findings alone and present or past history: sex, age $\geq 60$ years, BMI $\geq 30 \mathrm{~kg} / \mathrm{m}^{2}$, pulse pressure $\geq 65 \mathrm{mmHg}$, diastolic $\mathrm{BP} \geq 70 \mathrm{mmHg}$, heart rate $\geq 60$ beats $/ \mathrm{min}$, and history of stroke and smoking.
Model 2 included all variables in model 1, and also included the following laboratory data: $\mathrm{eGFR} \leq 65 \mathrm{~mL} / \mathrm{min} / 1.73 \mathrm{~m}^{2}$, BNP $70-175 \mathrm{pg} / \mathrm{mL}, \mathrm{BNP} \geq 175 \mathrm{pg} / \mathrm{mL}$, AST $\geq 50 \mathrm{IU} / \mathrm{L}$ or ALT $\geq 50 \mathrm{IU} / \mathrm{L}, \mathrm{HbA} 1 \mathrm{c}>7 \%$ and uric acid $\geq 6 \mathrm{mg} / \mathrm{dL}$. Model 3 included all variables in model 2 , and also included the following echocardiographic data: LAd $\geq 45 \mathrm{~mm}$, LVDd $\geq 55 \mathrm{~mm}$, and mean LVWT $\geq 14 \mathrm{~mm}$ and LVEF $\leq 45 \%$. Model 4 included all the covariates that were significantly associated with onset of $\mathrm{AF}$ with $\mathrm{P}$ values $<0.01$ in the univariable logistic regression analysis: age $\geq 60$ years, pulse pressure $\geq 65 \mathrm{mmHg}$, heart rate $\geq 60$ beats $/ \mathrm{min}$, eGFR $65 \mathrm{~mL} / \mathrm{min} / 1.73 \mathrm{~m}^{2}$, BNP $70-175 \mathrm{pg} / \mathrm{mL}$, BNP $\geq 175 \mathrm{pg} / \mathrm{mL}$, LAd $\geq 45 \mathrm{~mm}$, LVDd $\geq 55 \mathrm{~mm}$, mean LVWT 

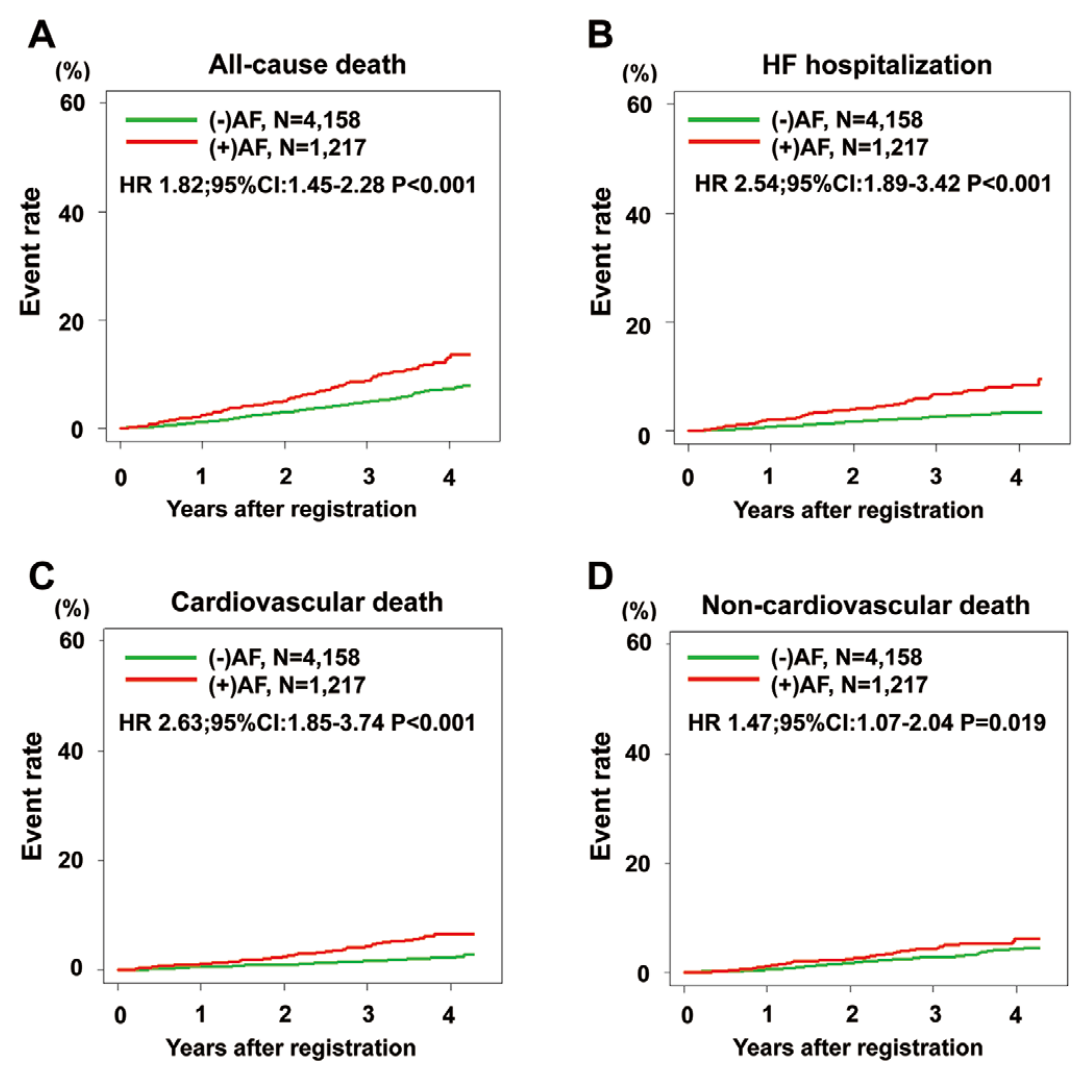

D

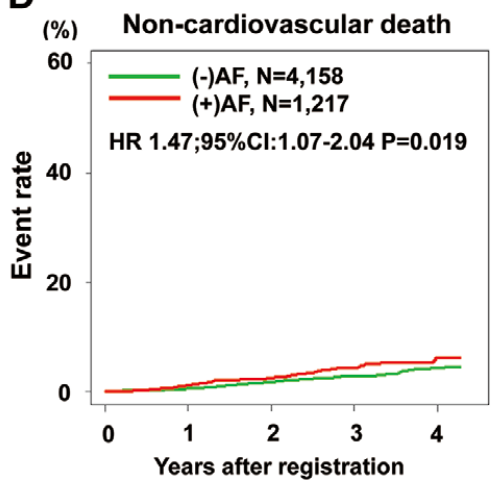

Figure 2. Kaplan-Meier curves for patients with $((+) A F)$ and without $A F$ $((-) A F)$ at the time of enrollment for (A) all-cause death, (B) heart failure hospitalization, (C) cardiovascular death and (D) non-cardiovascular death. AF, atrial fibrillation; $\mathrm{Cl}$, confidence interval; HF, heart failure; HR, hazard ratio. $\geq 14 \mathrm{~mm}$ and $\mathrm{LVEF}<45 \%$. An integer score equivalent to the odds ratio (OR) of the particular risk factor was initially assigned to each risk factor selected in model 4 . We then added and took back in turn the covariates from other models having score 1 , in order to obtain the best set of the risk score. Finally, the score assigned to the components of the risk score was increased and decreased in turn, to determine the risk score with the largest AUC.

For the internal validation of our risk score, we performed a simulation study, which was formed with iteration of random partition of the data into training and validation sets. ${ }^{38}$ First, we randomly divided the whole population data of 4,165 patients into 2,766 training $(66.7 \%)$ and 1,389 validation (33.3\%) sets, the latter being completely set aside during training. To train the model, the logistic regression model was applied to the training set with the covariates that were included in our AF risk score. Adjusted OR and respective scoring points for each covariate were determined by exactly the same method for the aforementioned full model described. The AF risk score obtained from the training data was applied to the samples in the validation set and the corresponding risk strata were predicted for each sample. This process was iterated 1,000 times and the median and IQR of the AUC of the receiveroperating characteristic curves were calculated. We also calculated the average incidence of new-onset of AF in each predicted risk stratum.

We also attempted to identify the best set of risk factors based on the covariates without echocardiographic data using the same protocol. The discriminatory power of the risk scores was estimated by the AUC. All statistical anal- ysis was performed using $\mathrm{R}$ software (version 3.2.1) ${ }^{39}$ and $\mathrm{P}<0.05$ was considered to be statistically significant.

\section{Results}

\section{Baseline Patient Characteristics}

The baseline characteristics of the patients with and without AF at enrollment are shown in Table 1A. Patients with AF at enrollment, as compared with those without it, were characterized by higher age, lower prevalence of DM, dyslipidemia and smoking, higher prevalence of prior stroke, lower eGFR, higher BNP, and a lower prevalence of IHD, but higher prevalence of DCM, HCM, VHD and HT. They were more frequently treated with $\beta$-blockers and diuretics and less frequently treated with statins. Table 1B shows the baseline characteristics of the patients with and without new AF, and those with $\mathrm{pAF}$ or npAF. The patients with new AF, as compared with those without it, were characterized by higher age, higher BNP level, lower eGFR and larger LAd. The patients with npAF, as compared with pAF patients, were characterized by a lower prevalence of IHD, lower LVEF, larger LAd and increased use of diuretics.

\section{Prognostic Impact of AF}

Among the 5,387 patients, 331 died and 180 were hospitalized for HF during the median follow-up period of 3.1 years. The cause of death was CV disease in 126, non-CV disease in 176 and unknown in 29. Figure 2 shows the results of Kaplan-Meier estimates and univariable Cox proportional hazard models for all-cause death, HF hospi- 
A

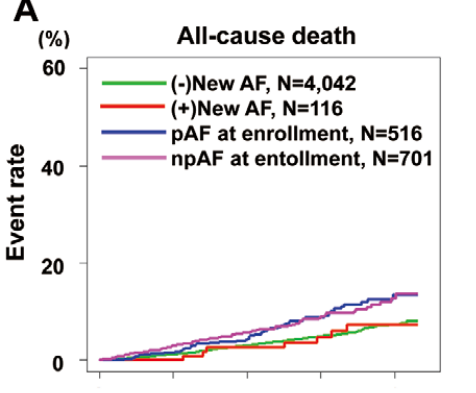

B

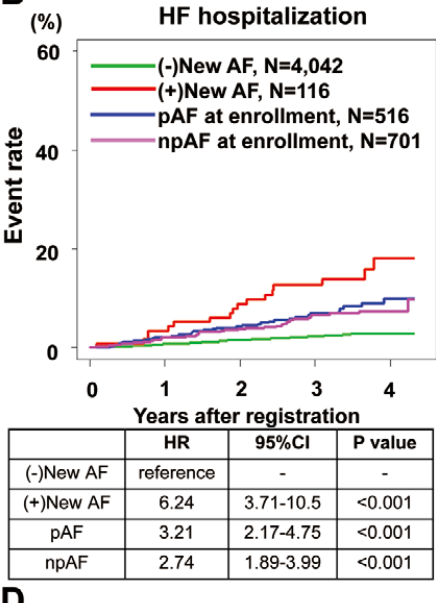

D

$\mathbf{C}_{(\%)} \quad$ Cardiovascular death

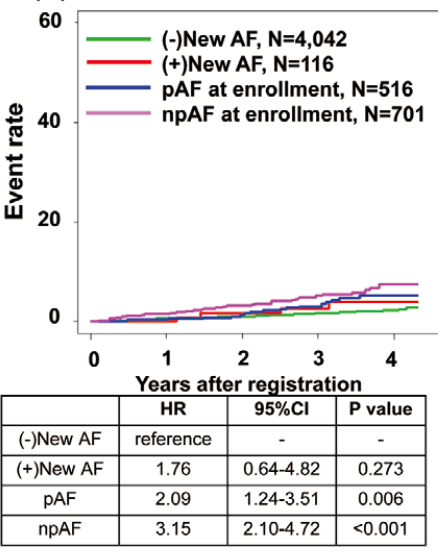

\begin{tabular}{|c|c|c|c|}
\multicolumn{4}{c}{ Years after registration } \\
\hline & HR & $\mathbf{9 5 \%} \mathrm{Cl}$ & P value \\
\hline (-)New AF & reference & - & - \\
\hline (+)New AF & 1.13 & $0.56-2.30$ & 0.728 \\
\hline pAF & 1.84 & $1.35-2.51$ & $<0.001$ \\
\hline npAF & 1.82 & $1.37-2.40$ & $<0.001$ \\
\hline
\end{tabular}
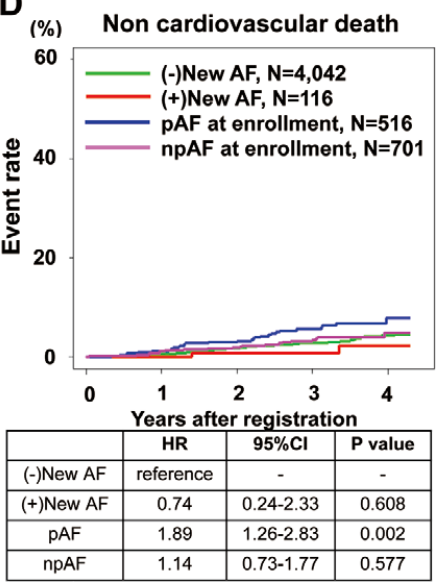

E

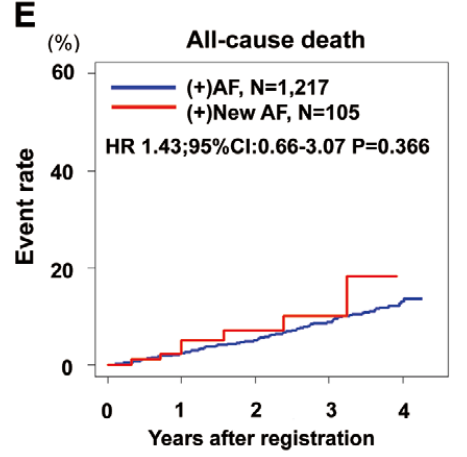

$\mathbf{F}$

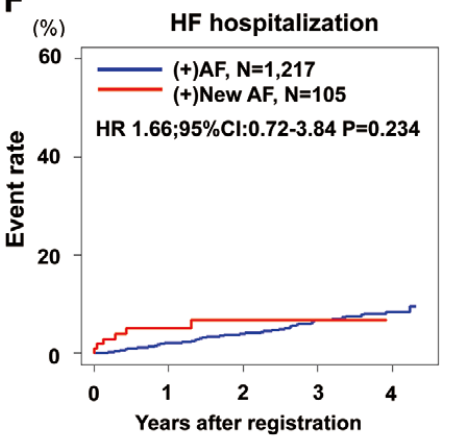

Figure 3. Kaplan-Meier curves for patients with paroxysmal $A F(p A F)$, non-paroxysmal $A F(n p A F)$, or without $A F((-) A F)$ at the time of enrollment and those with new-onset AF $((+)$ New AF) for $(\mathbf{A})$ all-cause death, $(\mathbf{B})$ heart failure hospitalization, (C) cardiovascular death and (D) non-cardiovascular death. Kaplan-Meier curves for (E) all-cause death and (F) HF hospitalization after the post-enrollment onset of new AF in patients with HF. Abbreviations as in Figure 2.

talization, $\mathrm{CV}$ death and non-CV death. AF at enrollment was significantly associated with an increased incidence of each event.

Among the 4,165 patients without AF at enrollment, $116(2.8 \%)$ newly developed AF during the follow-up period. As compared with patients without new-onset AF $(n=4,042)$, this group had an increased risk of HF hospitalization (Figure 3B), but not for all-cause death (Figure 3A), CV death (Figure 3C), or non-CV death (Figure 3D). Both the patients with pAF and those with $\mathrm{npAF}$ had increased mortality rates and risk of HF hospitalization (Figure 3A-D).

Multivariable Cox proportional hazard models showed that AF at enrollment was significantly associated with increased all-cause death and HF hospitalization, even after adjustment for clinical variables (Figure 4A), whereas new-onset AF was only associated with increased HF hospitalization (Figure 4B). Among AF patients, only pAF was associated with increased HF hospitalization (Figure 4B). The prognosis of patients with new-onset AF, as observed from the time of onset, was comparable with that of patients with $\mathrm{AF}$ at the time enrollment (Figure 3E,3F).
Notably, no significant interaction was noted between the prognostic impact of new AF and sex (Table S1).

\section{Factors Associated With AF and Development of Risk Score}

Among the patients without AF at enrollment, 116 developed AF during the follow-up period. The factors related to new-onset AF are shown in Table 2. The addition of smoking and pulse pressure as covariates to model 4 increased the AUC. The risk factors and highest scores assigned for each factor with the largest AUC (0.76) are shown in Table 3. The obtained AUC value was similar between male and female patients $(0.76$ and 0.77 , respectively), and was also similar and high enough between patients with and without IHD $(0.79$ and 0.72 , respectively). The incident rate of new-onset AF clearly increased as the sum of the risk score increased (Figure $\mathbf{5 A}$ ).

Based on the total risk score, the patients were stratified into 3 risk groups for new-onset AF; low risk (score 0-3, $\mathrm{n}=1,919$ ), intermediate risk (score 4-8, n=927), and high risk (score 9-13, n=89) (Figure 5A). The intermediate- and high-risk groups were significantly associated with an 


\begin{tabular}{|c|c|c|c|c|}
\hline \multicolumn{5}{|l|}{$\mathbf{A}$} \\
\hline & & Events / N & $\mathrm{HR}(95 \% \mathrm{Cl})$ & $P$ value \\
\hline \multicolumn{5}{|l|}{ All-cause death } \\
\hline$(-) A F$ & $i$ & $202 / 3,705$ & Reference & \\
\hline$(+) \mathrm{AF}$ & $\bullet$ & $105 / 1,144$ & $1.31(1.03-1.68)$ & 0.027 \\
\hline \multicolumn{5}{|l|}{ HF hospitalization } \\
\hline$(-) \mathrm{AF}$ & $\varphi$ & $88 / 3,147$ & Reference & \\
\hline$(+) A F$ & $\longmapsto$ & 62 / 981 & $1.74(1.24-2.45)$ & 0.001 \\
\hline HR 0 & $\begin{array}{lll}1 & 2 & 3\end{array}$ & & & \\
\hline \multicolumn{4}{|c|}{$\mathrm{HR}(95 \% \mathrm{Cl}) \quad \mathrm{P}$ value } & $P$ value \\
\hline \multicolumn{5}{|l|}{ All-cause death } \\
\hline$(-)$ New AF & 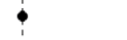 & $195 / 3,599$ & Reference & \\
\hline$(+)$ New AF & 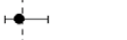 & $7 / 106$ & $0.88(0.41-1.87)$ & 0.738 \\
\hline $\mathrm{pAF}$ & $\bullet$ & $45 / 484$ & $1.33(0.96-1.85)$ & 0.085 \\
\hline npAF & $\bullet$ & $60 / 660$ & $1.29(0.96-1.74)$ & 0.097 \\
\hline \multicolumn{5}{|l|}{ HF hospitalization } \\
\hline$(-)$ New AF & 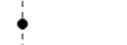 & $74 / 3,010$ & Reference & \\
\hline$(+)$ New AF & $\longmapsto$ & $-13 / 89$ & $4.24(2.32-7.74)$ & $<0.001$ \\
\hline $\mathrm{pAF}$ & $\longmapsto$ & $28 / 403$ & $1.97(1.61-3.95)$ & $<0.001$ \\
\hline npAF & $\bullet$ & $34 / 568$ & $1.30(0.79-2.14)$ & 0.297 \\
\hline HR 0 & 13 & 5 & & \\
\hline \multicolumn{5}{|c|}{$\begin{array}{l}\text { Figure 4. Prognostic impact of atrial fibrillation at enrollment } \\
\text { and new-onset AF. Forrest plots for multivariable Cox propor- } \\
\text { tional regression analysis for all-cause death and heart failure } \\
\text { hospitalization comparing }(\mathbf{A})(-) A F \text { and }(+) A F \text {, and }(\mathbf{B})(-) A F \text {, } \\
(+) A F \text { and }(+) \text { New AF. Abbreviations as in Figure } 2 \text {. }\end{array}$} \\
\hline
\end{tabular}

increased incidence of new-onset AF compared with the low-risk group (hazard ratio [HR]: 5.2, 95\% confidence interval [CI]: $3.08-8.72, \mathrm{P}<0.001$ for the intermediate-risk group and HR: $15.2,95 \% \mathrm{CI}: 7.66-30.0, \mathrm{P}<0.001$ for the high-risk group) (Figure 5B). The results of the same evaluation performed without echocardiographic data are shown in Figure S1. Using this analytical approach, the AUC value was 0.72 , which was lower than the score obtained using the model that included echocardiographic data (AUC 0.76), and the incident rate of new-onset AF increased as the sum of the risk score increased (Figure S1). Notably, the value assigned to eGFR as a covariate increased from 1 to 2 (Table S2).

For internal validation of the accuracy of our risk score, we performed a simulation study with 1,000 runs of iteration. The median AUC of our score in the validation set was 0.71 (training AUC: median $=0.76, \mathrm{IQR}=0.03$; validation AUC: median=0.71, IQR=0.061).

\section{Discussion}

The major findings of the present study were: (1) $22.6 \%$ of patients with Stage A/B HF had AF at enrollment; (2) of the 4,165 patients without AF at enrollment, 116 newly developed AF during the median 3.1-year follow-up period; (3) AF at enrollment was associated with increased incidence of both all-cause death and HF hospitalization, whereas new AF was associated with HF hospitalization but not with all-cause death; and (4) the risk score developed based on the results of multivariable analysis was able to stratify the risk of AF development with reasonable accuracy in Stage A/B HF patients.

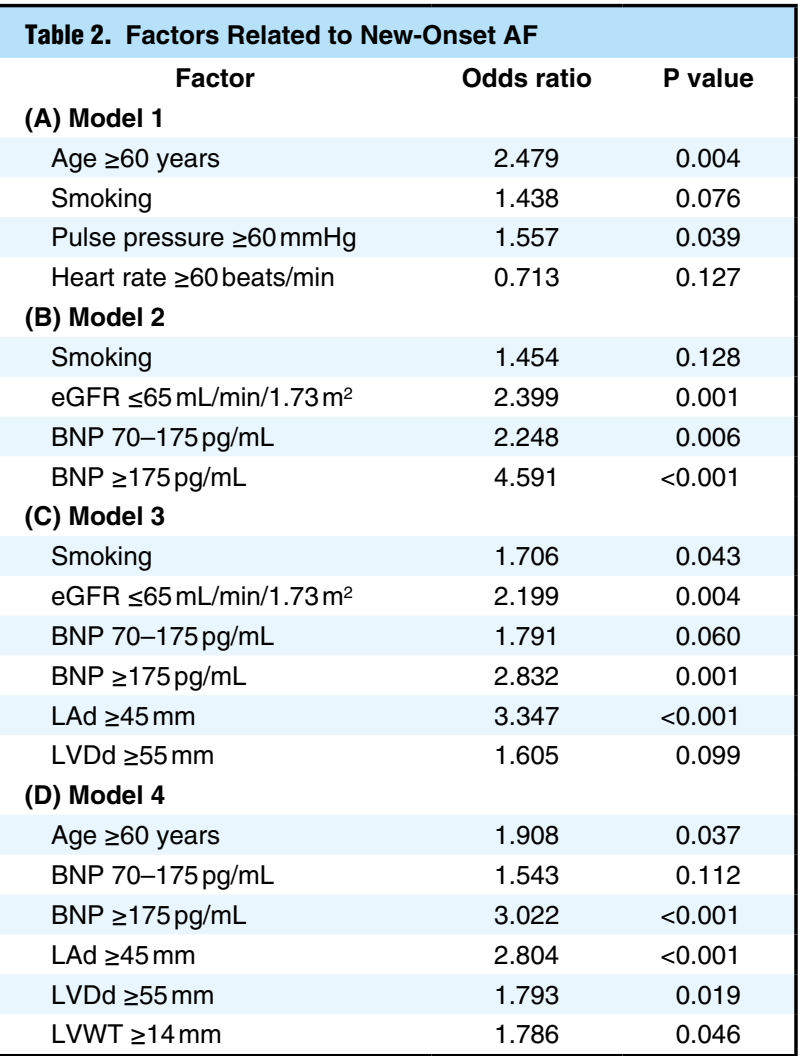

LV, left ventricle. Other abbreviations as in Table 1.

\begin{tabular}{|c|c|}
\hline Risk factor & Score \\
\hline Age $\geq 60$ years & 1 \\
\hline Smoking & 1 \\
\hline Pulse pressure $\geq 65 \mathrm{mmHg}$ & 1 \\
\hline eGFR $\leq 65 \mathrm{~mL} / \mathrm{min} / 1.73 \mathrm{~m}^{2}$ & 1 \\
\hline BNP $70-175 \mathrm{pg} / \mathrm{mL}$ & 1 \\
\hline $\mathrm{BNP} \geq 175 \mathrm{pg} / \mathrm{mL}$ & 3 \\
\hline $\mathrm{LAd} \geq 45 \mathrm{~mm}$ & 3 \\
\hline LVDd $\geq 55 \mathrm{~mm}$ & 2 \\
\hline LVWT $\geq 14 \mathrm{~mm}$ & 1 \\
\hline
\end{tabular}

Abbreviations as in Tables 1,2.

\section{Prevalence, Patients' Characteristics and Related Factors of $\mathrm{AF}$}

In the present study of Stage $\mathrm{A} / \mathrm{B} \mathrm{HF}$ patients in the CHART-2 Study, the prevalence of AF was $22.6 \%$ at enrollment. Although this rate is lower than previously reported in CHF patients, ${ }^{11-13}$ it is markedly higher than that of the general population $(1.0-2.1 \%)$, even considering the higher median age of the present cohort. ${ }^{1-4}$ Consistent with previous reports, $\mathbf{5 , 7 , 1 5 , 4 0}$ the patients with AF were characterized by higher age but lower prevalence of DM and IHD.

In the present study, the factors related to the risk of new-onset AF included higher age, smoking, pulse pressure, eGFR, BNP, LAd, LVDd, and LVWT. Of these, higher age, ${ }^{41}$ smoking, ${ }^{41}$ pulse pressure, ${ }^{42}$ eGFR ${ }^{43}$ and 


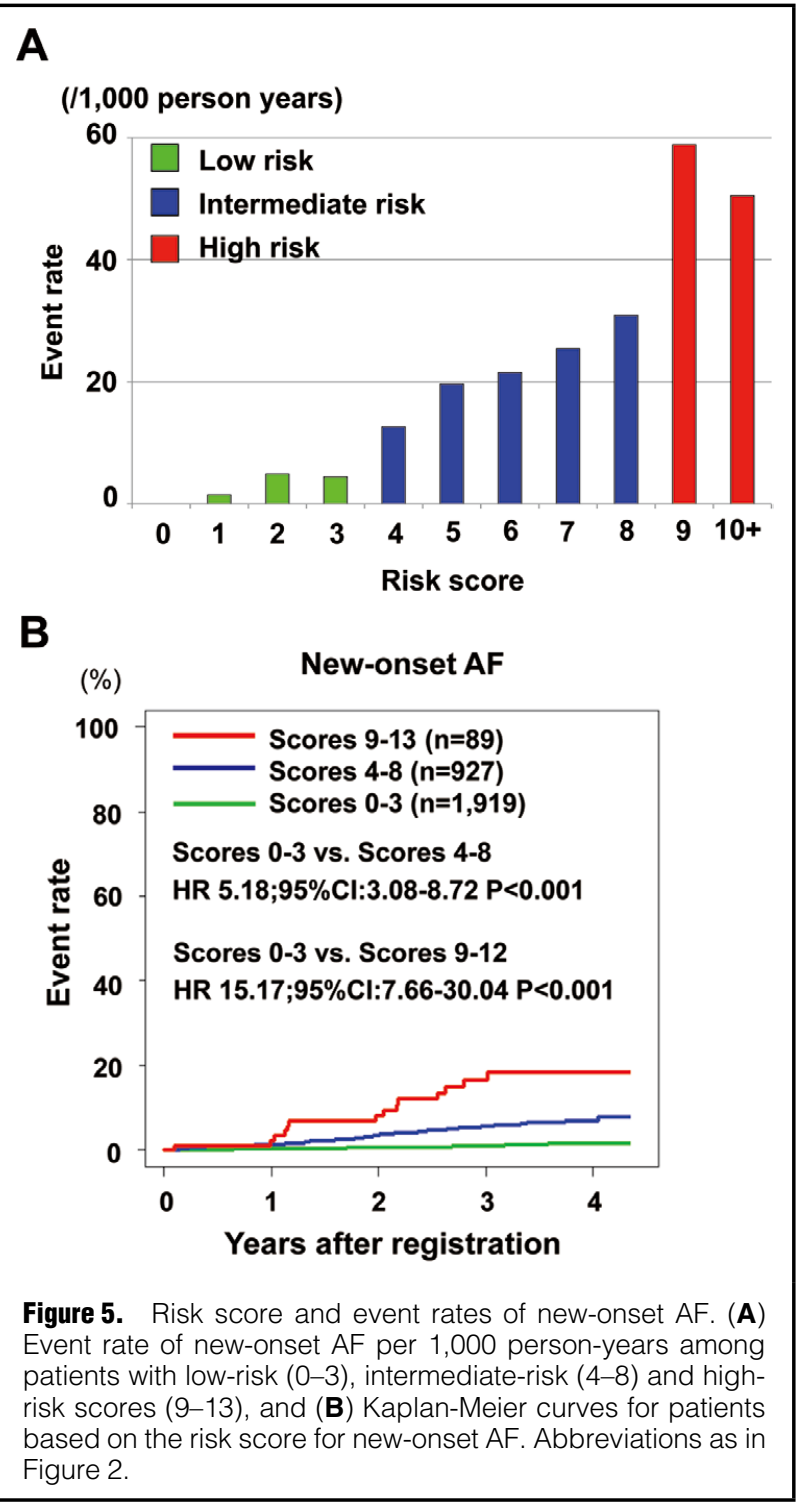

$\mathrm{BNP}^{44}$ were also previously found to be major factors for AF. Interestingly, the stepwise selection in the multivariable Cox proportional hazard models in the present study included pulse pressure, but not HT, because pulse pressure, a surrogate measure for aortic stiffness, ${ }^{45}$ may more accurately reflect the effect of long-term pressure load than systolic BP. Otherwise, a higher use of RAS inhibitors may have reduced the effect of systolic BP or history of HT on the onset of $\mathrm{AF}$ in the Stage A/B patients in the present study. LAd, LVDd, and LVWT on echocardiography, reflecting LV volume and pressure load, ${ }^{46,47}$ were also factors related to new-onset AF in the present study. As LA and $\mathrm{LV}$ remodeling on ECG were previously found to be related to new-onset $\mathrm{AF},{ }^{24}$ the corresponding values determined from echocardiography analysis in the present study may be related to new-onset AF.

\section{Prognostic Impact of AF}

In the present study, AF at enrollment was associated with poor prognosis for both all-cause death and HF hospitalization even after adjustment for possible confounding factors, a finding consistent with previous reports in the general population and in patients with aortic valve stenosis or CAD..$^{-7,15,40}$ On the other hand, new-onset AF was associated with an increased incidence of HF hospitalization, but not with all-cause death in the present study. These findings suggest that, in patients in Stage A/B, the prognostic impact of AF on all-cause death may become more evident later than that on HF development. Interestingly, in patients with Stage C/D HF, we recently reported that new-onset AF without prior HF worsening was associated with poor prognosis, whereas no such association was noted for new-onset AF after hospitalization for worsening HF. ${ }^{11}$ Thus, the long-term follow-up of the CHART-2 cohort could provide further insight into the effect of new-onset AF on patients with Stage A/B HF, especially in relation to HF development.

\section{Risk Score for New-Onset AF}

In the present study, we developed a simple and reliable risk score for AF onset. Notably, our risk score had good discrimination ability, with an AUC 0.76, which is comparable to previous risk scores. ${ }^{23-25}$ Because our score included both laboratory and objective echocardiographic data, it may outweigh physical findings, such as the intensity of murmurs. Compared with previous scores, ${ }^{23,24}$ our risk score comprises fewer variables with a simple integer score ranging from 1 to 3 . The use of such a simple and objective score may allow easy discrimination of patients at high risk for AF, thereby enabling early diagnosis and treatment, or even prevention of AF. However, removing the echocardiographic data (e.g., LVH and LA and LV dilatation) from our full risk score, reduced the AUC, indicating the importance of these factors in reflecting the pressure and volume load of the heart. ${ }^{\mathbf{4 6 , 4 7}}$

Benefit of Prevention, Early Diagnosis and Treatment of AF The present risk score enabled identification of patients at high risk for HF and future development of AF. Because $\mathrm{AF}$ is often asymptomatic ${ }^{\mathbf{1 8 , 4 8 - 5 0}}$ and is associated with similar risk of stroke regardless of its type (symptomatic vs. asymptomatic or paroxysmal vs. non-paroxysmal), ${ }^{17,51}$ a simple risk score to identify patients at high risk of AF may be clinically important to improve their prognosis. In other words, identification of patients at high risk for AF development may help to prevent $\mathrm{AF}$, resulting in a decrease in $\mathrm{HF}$ exacerbation, because new-onset $\mathrm{AF}$ was associated with increased incidence of admission for HF in the present study. Although continuous monitoring is effective for detecting new-onset AF, ${ }^{\mathbf{4 8 , 5 2}}$ such an approach may not be feasible for all patients with Stage A/B HF from a cost-effectiveness viewpoint.

\section{Study Limitations}

Several limitations of the present study should be mentioned. First, the mean age of the patients was relatively high and all patients were Japanese. Considering the possible effect of racial differences, ${ }^{22}$ this might limit the application of our risk score to other cohorts. Second, we had insufficient ECG data other than cardiac rhythm, with which the accuracy of the risk score could have been improved. Third, inclusion of the echocardiographic data may limit the application of the present risk score in the general population. Finally, although we performed an internal validation analysis and confirmed the reproducibility and accuracy of our score, external validation was 
not performed. Thus, our results remain to be confirmed in other cohorts and populations.

\section{Conclusions}

In the present study, we demonstrated that $\mathrm{AF}$ was associated with worse prognosis in patients at high risk of HF. We also developed a simple and accurate risk score to identify patients at high risk for AF onset. Further studies are needed to confirm our findings and to validate the risk score in other populations.

\section{Acknowledgments}

We thank all the members of the Tohoku Heart Failure Association and the staff of the Departments of Cardiovascular Medicine and Evidence-based Cardiovascular Medicine, Tohoku University Graduate School of Medicine for their contributions (see Supplementary File 1).

\section{Funding Sources}

This study was supported in part by Grants-in Aid from the Ministry of Health, Labour, and Welfare, the Ministry of Education, Culture, Sports, Science, and Technology and the Agency for Medical Research and Development (No. 15ek0210043h0001, No. 16ek0210043h0002, No. 16ek0210056h0001), Tokyo, Japan.

\section{Disclosures}

The Department of Evidence-based Cardiovascular Medicine, Tohoku University Graduate School of Medicine is supported in part by unrestricted research grants from Daiichi Sankyo Co., Ltd. (Tokyo, Japan), Bayer Yakuhin, Ltd. (Osaka, Japan), Kyowa Hakko Kirin Co., Ltd. (Tokyo, Japan), Kowa Pharmaceutical Co., Ltd. (Tokyo, Japan), Novartis Pharma K.K. (Tokyo, Japan), Dainippon Sumitomo Pharma, Co., Ltd. (Osaka, Japan), Nippon Boehringer Ingelheim Co., Ltd. (Tokyo, Japan), Astellas Pharma (Tokyo, Japan), AstraZeneca (Osaka, Japan), Chugai Pharmaceutical (Tokyo, Japan), GlaxoSmithKline (Tokyo, Japan), Mitsubishi Tanabe Pharma (Osaka, Japan), Mochida Pharmaceutical (Tokyo, Japan), MSD (Tokyo, Japan), Otsuka Pharmaceutical (Tokyo, Japan), Shionogi (Osaka, Japan) and Takeda Pharmaceutical (Tokyo, Japan). H.S. has received lecture fees from Bayer Yakuhin, Ltd. (Osaka, Japan), Daiichi Sankyo Co., Ltd. (Tokyo, Japan) and Novartis Pharma K.K. (Tokyo, Japan).

\section{References}

1. Wolf PA, Abbott RD, Kannel WB. Atrial fibrillation as an independent risk factor for stroke: The Framingham Study. Stroke 1991; 22: 983-988.

2. Majeed A, Moser K, Carroll K. Trends in the prevalence and management of atrial fibrillation in general practice in England and Wales, 1994-1998: Analysis of data from the general practice research database. Heart 2001; 86: 284-288.

3. Go AS, Hylek EM, Phillips KA, Chang YC, Henault LE, Selby $\mathrm{JV}$, et al. Prevalence of diagnosed atrial fibrillation in adults. JAMA 2001; 285: 2370-2375.

4. Furberg CD, Psaty BM, Manolio TA, Gardin JM, Smith VE, Rautaharju PM; for the CHS collaborative research group. Prevalence of atrial fibrillation in elderly subjects (the Cardiovascular Health Study). Am J Cardiol 1994; 74: 236-241.

5. Stewart S, Hart CL, Hole DJ, McMurray JJV. A populationbased study of the long-term risks associated with atrial fibrillation: 20-year follow-up of the Renfrew/Paisley Study. Am J Med 2002; 113: 359-364.

6. Krahn AD, Manfreda J, Tate RB, Mathewson FAL, Cuddy TE. The natural history of atrial fibrillation: Incidence, risk factors, and prognosis in the Manitoba follow-up study. Am J Med 1995; 98: $476-484$

7. Benjamin EJ, Wolf PA, D'Agostino RB, Silbershatz H, Kannel WB, Levy Daniel. Impact of atrial fibrillation of the risk of death. Circulation 1998; 98: 946-952.

8. Gage BF, Waterman AD, Shannon W, Boechler M, Rich MW, Radford MJ. Validation of clinical classification schemes for predicting stroke. JAMA 2001; 285: 2864-2870.

9. Hart RG, Pearce LA, Aguilar MI. Meta-analysis: Antithrombotic therapy to prevent stroke in patients who have nonvalvular atrial fibrillation. Ann Intern Med 2007; 146: 857-867.
10. Connolly SJ, Ezekowitz MD, Yusuf S, Eikelboom J, Oldgren J, Parekh A, et al. Dabigatran versus warfarin in patients with atrial fibrillation. $N$ Engl J Med 2009; 361: 1139-1151.

11. Yamauchi T, Sakata Y, Miura M, Tadaki S, Ushigome R, Sato $\mathrm{K}$, et al. Prognostic impact of new-onset atrial fibrillation in patients with chronic heart failure: A report from the CHART-2 Study. Circ J 2016; 80: 157-167.

12. Swedberg K, Olsson LG, Charlesworth A, Cleland J, Hanrath P, Komajda M, et al. Prognostic relevance of atrial fibrillation in patients with chronic heart failure on long-term treatment with beta-blockers: Results from COMET. Eur Heart J 2005; 26: $1303-1308$.

13. Olsson LG, Swedberg K, Ducharme A, Granger CB, Michelson EL, McMurray JJV, et al. Atrial fibrillation and risk of clinical events in chronic heart failure with and without left ventricular systolic dysfunction. J Am Coll Cardiol 2006; 47: 1997-2004.

14. Yancy CW, Jessup M, Bozkurt B, Butler J, Casey DE, Drazner $\mathrm{MH}$, et al. $2013 \mathrm{ACCF} / \mathrm{AHA}$ guideline for the management of heart failure. J Am Coll Cardiol 2013; 62: e147-e239.

15. Meyer ML, Jaensch A, Mons U, Breitling LP, Hahmann H, Koenig W, et al. Atrial fibrillation and long-term prognosis of patients with stable coronary heart disease: Relevance of routine electrocardiogram. Int J Cardiol 2016; 203: 1014-1015.

16. Wang TJ, Larson MG, Levy D, Vasan RS, Leip EP, Wolf PA, et al. Temporal relations of atrial fibrillation and congestive heart failure and their joint influence on mortality the Framingham Heart Study. Circulation 2003; 107: 2920-2925.

17. Hohnloser SH, Pajitnev D, Pogue J, Healey JS, Pfeffer MA, Yusuf S, et al. Incidence of stroke in paroxysmal versus sustained atrial fibrillation in patients taking oral anticoagulation or combined antiplatelet therapy: An ACTIVE W substudy. J Am Coll Cardiol 2007; 50: 2156-2161.

18. Tayal AH, Tian M, Kelly KM, Jones SC, Wright DG, Singh D, et al. Atrial fibrillation detected by mobile cardiac outpatient telemetry in cryptogenic TIA or stroke. Neurology 2008; 71: $1696-1701$.

19. Wachtell K, Lehto M, Gerdts E, Olsen MH, Hornestam B, Dahlof B, et al. Angiotensin II receptor blockade reduces newonset atrial fibrillation and subsequent stroke compared to atenolol. J Am Coll Cardiol 2005; 45: 712-719.

20. Ducharme A, Swedberg K, Pfeffer MA, Cohen-Solal A, Granger CB, Maggioni AP, et al. Prevention of atrial fibrillation in patients with symptomatic chronic heart failure by candesartan in the Candesartan in Heart failure: Assessment of Reduction in Mortality and morbidity (CHARM) program. Am Heart J 2006; 152: $86-92$

21. Pena JM, MacFadyen J, Glynn RJ, Ridker PM. High-sensitivity C-reactive protein, statin therapy, and risks of atrial fibrillation: An exploratory analysis of the JUPITER trial. Eur Heart $J$ 2012; 33: $531-537$.

22. Maggioni AP, Fabbri G, Lucci D, Marchioli R, Franzosi MG, Latini R, et al. Effects of rosuvastatin on atrial fibrillation occurrence: Ancillary results of the GISSI-HF trial. Eur Heart $J$ 2009; 30: $2327-2336$.

23. Schnabel RB, Sullivan LM, Levy D, Pencina MJ, Massaro JM, D'Agostino RB, et al. Development of a risk score for atrial fibrillation (Framingham Heart Study): A community-based cohort study. Lancet 2009; 373: 739-745.

24. Chamberlain AM, Agarwal SK, Folsom AR, Soliman EZ, Chambless LE, Crow R, et al. A clinical risk score for atrial fibrillation in a biracial prospective cohort (from the atherosclerosis risk in communities [ARIC] Study). Am J Cardiol 2011; 107: $85-91$.

25. Brunner KJ, Bunch J, Mullin CM, May HT, Bair TL, Elliot DW, et al. Clinical predictors of risk for atrial fibrillation: Implications for diagnosis and monitoring. Mayo Clin Proc 2014; 89: $1498-1505$.

26. Sakata Y, Shimokawa H. Epidemiology of heart failure in Asia. Circ J 2013; 77: 2209-2217.

27. Shimokawa H, Miura M, Nochioka K, Sakata Y. Heart failure as a general pandemic in Asia. Eur J Heart Fail 2015; 17: 884-892.

28. Pillai HS, Ganapathi S. Heart failure in South Asia. Curr Cardiol Rev 2013; 9: $102-111$.

29. Guo Y, Lip GY, Banerjee A. Heart failure in East Asia. Curr Cardiol Rev 2013; 9: 112-122.

30. Shiba N, Nochioka K, Miura M, Kohno H, Shimokawa H; on behalf of the CHART-2 investigators. Trend of westernization of etiology and clinical characteristics of heart failure patients in Japan. Circ J 2011; 75: 823-833. 
31. Miura M, Sakata Y, Miyata S, Nochioka K, Takada T, Tadaki $\mathrm{S}$, et al. Usefulness of combined risk stratification with heart rate and systolic blood pressure in the management of chronic heart failure: A report from the CHART-2 Study. Circ J 2013; 77: 2954-2962.

32. Miura M, Shiba N, Nochioka K, Takada T, Takahashi J, Kohno $\mathrm{H}$, et al. Urinary albumin excretion in heart failure with preserved ejection fraction: An interim analysis of the CHART-2 Study. Eur J Heart Fail 2012; 14: 367-76.

33. Nochioka K, Sakata Y, Takahashi J, Miyata S, Miura M, Takada T, et al. Prognostic impact of nutritional status in asymptomatic patients with cardiac diseases: A report from the CHART-2 Study. Circ J 2013; 77: 2318-2326.

34. Sakata Y, Miyata S, Nochioka K, Miura M, Takada T, Tadaki $\mathrm{S}$, et al. Gender differences in clinical characteristics, treatment and long-term outcome in patients with stage $\mathrm{C} / \mathrm{D}$ heart failure in Japan: Report from the CHART-2 Study. Circ J 2014; 78: $428-435$.

35. JCS Joint Working Group. Guidelines for pharmacotherapy of atrial fibrillation (JCS 2013): Digest version. Circ J 2014; 78: 1997-2021.

36. Venables WN, Ripley BD. Modern applied statistics with S. 4th edn. Springer, 2002.

37. Breiman L, Friedman JH, Olshen RA, Stone, CJ. Classification and regression trees. Monterey: Wadsworth and Brooks/Cole, 1984.

38. Hastie T, Tibshirani R, Friedman J. The elements of statistical learning: Data mining, inference, and prediction. 2nd edn. Springer series in statistics. Springer, 2009.

39. $\mathrm{R}$ core team. A language and environment for statistical computing. Vienna: R foundation for statistical computing, 2014. http://www.R-project.org (accessed March 30, 2016).

40. Levy F, Rusinaru D, Marechaux S, Charles V, Peltier M, Tribouilloy C. Determinants and prognosis of atrial fibrillation in patients with aortic stenosis. Am J Cardiol 2015; 116: 1541-1546.

41. Kirchhof P, Lip GYH, Gelder IC, Bax J, Hylek E, Kaab S, et al. Comprehensive risk reduction in patients with atrial fibrillation: Emerging diagnostic and therapeutic options: A report from the 3rd Atrial Fibrillation Competence NETwork/European Heart Rhythm Association consensus conference. Europace 2012; 14: 8-27.

42. Mitchell GF, Vasan RS, Keyes MJ, Parise H, Wang TJ, Larson $\mathrm{MG}$, et al. Pulse pressure and risk of new-onset atrial fibrillation. JAMA 2007; 297: 709-715.

43. Campbell NG, Cantor EJ, Sawhney V, Duncan ER, DeMartini $\mathrm{C}$, Baker V, et al. Predictors of new onset atrial fibrillation in patients with heart failure. Int $J$ Cardiol 2014; 175: 328-332.

44. Schnabel RB, Larson MG, Yamamoto JF, Sullivan LM, Pencina
MJ, Meigs JB, et al. Relations of biomarkers of distinct pathophysiological pathways and atrial fibrillation incidence in the community. Circulation 2010; 121: 200-207.

45. Mitchell GF, Lacourciere Y, Ouellet JP, Izzo JL, Neutel J, Kerwin $\mathrm{LJ}$, et al. Determinants of elevated pulse pressure in middle-aged and older subjects with uncomplicated systolic hypertension. Circulation 2003; 108: 1592-1598.

46. Grossman W, Jones D, McLaurin LP. Wall stress and patterns of hypertrophy in the human left ventricle. J Clin Invest 1975; 56: $56-64$.

47. McManus DD, Xanthakis V, Sullivan LM, Zachariah J, Aragam $\mathrm{J}$, Larson MG, et al. Longitudinal tracking of left atrial diameter over the adult life course: Clinical correlates in the community. Circulation 2010; 121: 667-674.

48. Camm AJ, Corbucci G, Padeletti L. Usefulness of continuous electrocardiographic monitoring for atrial firbrillaion. $\mathrm{Am} \mathrm{J}$ Cardiol 2012; 110: 270-276.

49. Patten M, Maas R, Karim A, Muller HW, Simonovsky R, Meinertz T. Event-recorder monitoring in the diagnosis of atrial fibrillation in symptomatic patients: Subanalysis of the SOPAT Trial. J Cardiovasc Electrophysiol 2006; 17: 1216-1220.

50. Fetsch T, Bauer P, Engberding R, Koch HP, Luki J, Meinertz T, et al. Prevention of atrial fibrillation after cardioversion: Results of the PAFAC trial. Eur Heart J 2004; 25: 1385-1394.

51. Flaker GC, Belew K, Beckman K, Vidaillet H, Kron J, Safford $\mathrm{R}$, et al. Asymptomatic atrial fibrillation: Demographic features and prognostic information from the Atrial Fibrillation Follow-up Investigation of Rhythm Management (AFFIRM) study. Am Heart J 2005; 149: 657-663.

52. Liao J, Khalid Z, Scallan C, Morillo C, O'Donnell M. Noninvasive cardiac monitoring for detecting paroxysmal atrial fibrillation or flutter after acute ischemic stroke. Stroke 2007; 38: 2935-2940.

\section{Supplementary File 1}

\section{Supplementary Files}

Figure S1. Risk score without echocardiography data and event rates of new-onset AF.

Table S1. Prognostic impact of new-onset AF by sex

Table S2. Values assigned to the risk factors of new-onset AF without echocardiographic data

\section{CHART-2 Study Investigators}

Please find supplementary file(s);

http://dx.doi.org/10.1253/circj.CJ-16-0759 